\title{
LEY DE PARTIDOS POLITICOS DE 4 DE DICIEMBRE DE 1978
}

Artículo $1 .{ }^{\circ}$

Los españoles podrán crear libremente partidos políticos en el ejercicio de su derecho fundamental de Asociación.

\section{Artículo 2. ${ }^{\circ}$}

1. Los partidos políticos adquirirán personalidad jurídica el vigesimoprimer día siguiente a aquel en que los dirigentes o promotores depositen, en el Registro que a estos efectos existirá en el Ministerio del Interior, acta notarial suscrita por los mismos, con expresa constancia de sus datos personales de identificación y en la que se inserten o incorporen los Estatutos por los que habrá de regirse el partido.

2. Dentro de los veinte días siguientes al depósito aludido en el apartado precedente, el Ministerio del Interior procederá a inscribir el partido en el Registro, sin perjuicio de lo que se dispone en el artículo siguiente. Si la inscripción se produjese antes de dicho término, el partido adquirirá personalidad jurídica a partir de la fecha de la misma.

Artículo 3. ${ }^{\circ}$

1. Si del examen de la documentación presentada se dedujesen indicios racionales de ilicitud penal de partido, el Ministerio del Interior lo pondrá en conocimiento del Ministerio Fiscal en el plazo de quince días, remitiéndole los documentos oportunos.

2. El Ministerio Fiscal, en el plazo de veinte días, a la vista de la documentación remitida, acordará su devolución al Registro, si estimare que no existen indicios de ilicitud penal. En caso contrario, instará de la 
autoridad judicial competente la declaración de ilegalidad del partido.

3. El ejercicio de la acción por el Ministerio Fiscal suspenderá el transcurso del plazo previsto en el apartado $1 .^{\circ} \mathrm{del}$ artículo anterior, así como la obligación del Ministerio del Interior de proceder a la inscripción del partido, en tanto no recaiga resolución judicial.

Artículo $4^{\circ}$

1. La organización y funcionamiento de los partidos políticos deberá ajustarse a principios democráticos.

2. El órgano supremo estará constituido por la Asamblea general del conjunto de sus miembros, que podrán actuar directamente o por medio de compromisarios.

Todos los miembros del partido tendrán derecho a ser electores y elegibles para los cargos del misme y acceso a la información sobre sus actividades y situación económica. Los órganos directores se proveerán en todo caso mediante sufragio libre y secreto. Los Estatutos de los partidos regularán los anteriores extremos.

Artículo $5 .^{\circ}$

1. La suspensión y disolución de los partidos políticos sólo podrá acordarse por decisión de la autoridad judicial competente.

2. La disolución de los partidos sólo podrá declararse en los siguientes casos:

a) Cuando incurran en supuestos tipificados, como de asociación ilícita en el Código Penal.

b) Cuando su organización o actividades sean contrarias a los principios democráticos.

3. En los procesos a que se refiere el apartado anterior, el órgano judicial competente, de oficio o a instancias de parte, podrá acordar la suspensión provisional del partido hasta que se dicte sentencia.

Artículo 6. ${ }^{\circ}$

La Administración del Estado financiará las actividades de los partidos con arreglo a las siguientes normas:

a) Cada partido recibirá anualmente una cantidad fija por cada escaño obtenido en cada una de las dos Cámaras y, asimismo, una cantidad fija por cada uno de los votos obtenidos por cada candidatura a cada una de las dos Cámaras. 
b) En los Presupuestos Generales del Estado se consignará la cantidad global destinada a estos fines, así como los criterios para distribuirla con sujeción a los dispuesto en el apartado anterior.

c) Reglamentariamente se determinará el régimen de distribución de las cantidades mencionadas en el apartado a) cuando los partidos hubieran concurrido a las elecciones formando parte de federaciones o coaliciones.

\section{Disposición transitoria}

Los partidos y asociaciones políticas que hayan sido inscritos con anterioridad a la entrada en vigor de la presente ley, conservarán su personalidad jurídica y la plenitud de su capacidad y derechos adquiridos, sin necesidad de ninguna adaptación de sus Estatutos.

\section{Disposiciones finales}

Primera. La presente ley entrará en vigor el día siguiente al de su publicación en el Boletín Oficial del Estado.

Segunda. Quedan derogados los siguientes preceptos de la Ley 21/ 1976, de 14 de junio: apartados 1 y 3 del artículo 1. ${ }^{\circ}$; apartados 2,3 y 4 del artículo 2. ${ }^{\circ}$; apartados 1, 2 letra b), segunda frase, y apartado 3 del artículo 3. ${ }^{\circ}$; apartados 2, párrafo segundo, 3, 4, 5 y 6 del artículo 4. ${ }^{\circ}$; apartados 2, 3,4 y 5 del artículo $6 .^{\circ}$; apartados 1 y 2 del artículo $7 .^{\circ}$ y el artículo $8 .^{\circ}$ Igualmente queda derogado el Real Decreto-ley 12/1977, de 8 de febrero.

Ley 62/1978, de 26 de diciembre, de Protección Jurisdiccional de los Derechos Fundamentales de la Persona.

De conformidad con la Ley aprobada por las Cortes, vengo en sancionar:

Artículo 1.0

1. El ejercicio de los derechos fundamentales de la persona, comprendidos en el ámbito de aplicación de esta Ley, gozará de las garantías jurisdiccionales que en la misma se establecen.

2. Quedan comprendidas en el ámbito de aplicación de esta Ley, sin perjuicio de lo establecido en su disposición final, las libertades de expresión, reunión y asociación, la libertad y secreto de la correspondencia, la libertad religiosa y la de residencia, la garantía de la inviolabilidad del 
domicilio, la protección jurídica frente a las detenciones ilegales $\mathrm{y}$, en general, frente a las sanciones impuestas en materia de orden público.

\section{SECCION PRIMERA}

\section{Garantía jurisdiccional penal}

Artículo 2.

1. Los delitos y faltas contra los derechos fundamentales de la persona, comprendidos en el ámbito de aplicación de esta Ley, serán enjuiciados por los Juzgados y Tribunales de la jurisdicción ordinaria, según su propia competencia.

2. Para el enjuiciamiento de estos delitos y faltas se observarán las normas de procedimiento correspondientes de la Ley de Enjuiciamiento Criminal.

3. Cuando el conocimiento y fallo corresponda a la Audiencia Provincial, el trámite utilizado será el que dispone el capítulo III del título III del libro IV de dicha Ley de Enjuiciamiento Criminal con las siguientes modificaciones:

Primera. Los artículos de previo pronunciamiento se propondrán en el escrito de calificación provisional y serán resueltos en la sentencia definitiva.

Segunda. El plazo para instrucción y calificación que concede el artículo setecientos noventa y siete de la Ley de Enjuiciamiento Criminal se entenderá común, y de cinco días, para todas las partes acusadoras, y también común, y de la misma duración, para las partes acusadas.

\section{Artículo 3. ${ }^{\circ}$}

1. Para el enjuiciamiento de los delitos cometidos a través de la imprenta, el grabado $\mathrm{u}$ otros medios mecánicos de publicación, sonoros o fotográficos, difundidos por escrito, radio, televisión, cinematógrafo u otros similares, se seguirán los trámites señalados en el título $\mathrm{V}$ del libro IV de la Ley de Enjuiciamiento Criminal, con las modificaciones señaladas en el párrafo tres del artículo anterior.

2. Los jueces, al iniciar el procedimiento, podrán acordar, según los casos, el secuestro de la publicación o la prohibición de difundir o proyectar el medio a través del cual se produjo la actividad delictiva. Contra 
dicha resolución podrá interponerse directamente recurso de apelación, que deberá ser resuelto en el plazo de cinco días.

\section{Artículo $4 .^{\circ}$}

1. Cuando los delitos a que se refiere el artículo anterior sean los de calumnia o injuria, previstos y penados en los capítulos primero y segundo del título $\mathrm{X}$ del libro II del Código Penal, en los supuestos a que se refiere el artículo cuatrocientos sesenta y tres del mismo texto, bastará denuncia de la persona agraviada o, en su caso, de su representante legal, sin necesidad de acto de conciliación.

2. El perdón del ofendido o, en su caso, del representante legal extingue la acción legal o la pena impuesta o en ejecución.

3. Lo establecido en el párrafo anterior se aplicará también a las injurias livianas a que se refiere el número uno del artículo quinientos ochenta y seis del Código Penal.

4. Las ofensas dirigidas a la Autoridad pública. Corporaciones o clases determinadas del Estado y lo dispuesto en el capítulo VIII del título II del libro II del Código Penal no sufrirán alteración en su actual sistema de persecución como delitos públicos.

5. La indemnización por perjuicios materiales y morales será fijada en la sentencia expresamente. Los Tribunales tendrán en cuenta el agravio producido y el medio a través del cual se cometiera el delito o falta, así como la difusión del mismo.

\section{Artículo 5.}

1. La tramitación de las causas a que se refieren los artículos anteriores tendrá carácter urgente y preferente, y su duración, desde la iniciación del procedimiento hasta la sentencia, no podrá exceder de sesenta días en las del artículo segundo ni de cuarenta y cinco en las del artículo tercero.

\section{SECCION SEGUNDA}

\section{Garantía contencioso-administrativa}

Artículo 6.

1. Contra los actos de la Administración pública, sujetos a Derecho administrativo, que afecten al ejercicio de los derechos fundamentales de 
la persona, mencionados en el artículo primero, dos, de esta Ley, podrá interponerse recurso contencioso-administrativo de conformidad con las reglas de procedimiento establecidas en la presente sección y, a falta de previsión especial, de acuerdo con las reglas generales de la Ley de la Jurisdicción Contenciso-Administrativa, cuya aplicación será supletoria.

\section{Artículo $7 .^{\circ}$}

1. Para la interposición de estos recursos no será necesaria la reposición ni la utilización de cualquier otro recurso previo administrativo.

2. En el mismo escrito de interposición del recurso contencioso-administrativo, o en cualquier momento posterior, podrá solicitarse la suspensión de la efectividad del acto administrativo impugnado.

3. De esta solicitud, y en pieza separada, se dará traslado al Ministerio Fiscal y al Abogado del Estado, y se requerirá al órgano del que dimane el acto impugando para que en el plazo de cinco días puedan informar acerca de la solicitud de suspensión.

4. Deducidos los dictámenes e informes a que se refiere el párrafo anterior o transcurrido el plazo concedido al efecto la Sala acordará la suspensión del cumplimiento del acto impugnado, salvo que se justifique la existencia o posibilidad de perjuicio grave para el interés general, suspensión que podrá concederse con o sin afianzamiento de los perjuicios de cualquiera otra naturaleza que pudieran derivarse.

5. La interposición del recurso contencioso-administrativo suspenderá, en todo caso, la resolución administrativa cuando se trate de sanciones pecuniarias reguladas por la Ley de Orden Público, sin necesidad de afianzamiento o depósito alguno ni de los dictámenes a que se refiere el apartado anterior.

6. En el caso de prohibición o de propuesta de modificación de reuniones previstas en la Ley Reguladora del Derecho de Reunión que no fueren aceptadas por los promotores, éstos podrán interponer recurso contencioso-administrativo ante la Audiencia competente, poniendo, al mismo tiempo, en conocimiento de la autoridad tal interposición para que ésta remita inmediatamente el expediente a la Audiencia. Dentro del plazo improrrogable de cinco días, el Tribunal, poniendo de manifiesto el expediente, convocará al Abogado del Estado, al Ministerio Fiscal y a los promotores o a la persona que éstos designen como su representante, a una audiciencia en la que, de manera contradictoria, oirá a todos los personados y resolverá sin ulterior recurso sobre el mantenimiento o revocación de la prohibición o de las modificaciones propuestas. 
Artículo 8. ${ }^{\circ}$

1. El recurso contencioso-administrativo se interpondrá dentro de los diez días siguientes a la notificación del acto impugnado, si fuere expreso. En caso de silencio administrativo, el plazo anterior se computará una vez transcurridos veinte días desde la solicitud del interesado ante la Administración, sin necesidad de denunciar la mora.

2. En el mismo día de la presentación o en el siguiente, la Sala requerirá por vía telegráfica y con carácter urgente al órgano administrativo correspondiente para que en el plazo de cinco días, a contar desde la recepción del requerimiento, remita el expediente y pueda alegar lo que estime procedente como fundamento del acto impugnado, con apercibimiento de cuanto establece el apartado cuatro del artículo diez de esta Ley.

La resolución administrativa que ordene la remisión del expediente se notificará de inmediato a todos los interesados en el mismo, emplazándoles para que puedan comparecer ante la Sala en el plazo de cinco días.

3. La falta de envío del expediente administrativo dentro del plazo previsto en el párrafo anterior no suspenderá el curso de los autos. Tampoco lo suspenderá la falta de alegaciones por parte de la Administración.

4. Recibido el expediente o transcurrido el plazo para su remisión y, en su caso, el del emplazamiento a los demás interesados, la Sala, dentro del siguiente día, pondrá de manifiesto el expediente y demás actuaciones al recurrente para que en el plazo improrrogable de ocho días pueda formalizar la demanda y aportar la documentación que estime conveniente. Acto seguido se dará traslado al Ministerio Fiscal, al Abogado del Estado y a quienes se hubieren personado, para que en el plazo común e improrrogable de ocho días efectúen, en su caso, las alegaciones que estimen pertinentes. A los escritos de contestación a la demanda podrá acompañarse la documentación que se considere oportuna.

5. Cuando el expediente administrativo se recibiese en el Tribunal una vez transcurrido el plazo establecido en el apartado dos de este artículo, se pondrá de manifiesto a las partes por término de veinticuatro horas y $\sin$ alteración del curso del procedimiento.

6. Transcurrido el plazo señalado en el apartado cuatro anterior, con o sin alegaciones, la Sala decidirá en el siguiente día sobre el recibimiento a prueba en su caso. El periodo probatorio no será superior a veinte días, comunes para la proposición y práctica, a prudente arbitrio de la Sala, sin que en ningún supuesto sea procedente el término extraordinario.

7. Conclusas las actuaciones, la Sala, sin más trámites, pero con citación de las partes, dictará sentencia en el plazo de tres días. 
Artículo 9.

1. Contra la sentencia podrá interponerse, en su caso, recurso de apelación, en un solo efecto, ante el Tribunal Supremo.

2. la apelación se preparará mediante escrito razonado ante la Sala sentenciadora, dentro del plazo de cinco días común a todas las partes personadas.

3. Admitido el recurso, en su caso, se remitirán las actuaciones a la Sala del Tribunal Supremo que corresponda, con emplazamiento a las partes por cinco días para que puedan personarse si lo consideran oportuno.

4. Si dentro del término del emplazamiento no compareciere el apelante, se declarará desierto el recurso, imponiéndole las costas.

5. Comparecido el apelante y transcurrido el término de los emplazamientos, la Sala dictará sentencia en el plazo de cinco días.

Artículo 10

1. La tramitación de estos recursos tendrá carácter urgente a todos los efectos orgánicos y procesales.

2. La puesta de manifiesto de las actuaciones se sustituirá, cuando sea posible, por la entrega de fotocopia de las mismas, debidamente cotejada.

3. Las costas se impondrán al recurrente o a la Administración pública si fueren rechazadas o aceptadas, respectivamente, todas sus pretensiones. En otro caso se seguirán las reglas comunes.

4. Si la Administración que hubiese dictado el acto impugnado no remitiera el expediente dentro del plazo señalado en el apartado dos del artículo octavo, se deducirá sin más trámites ni recordatorio alguno el oportuno testimonio de particulares para exigir la responsabilidad personal y directa por desobediencia en que hubiera podido incurrir el Jefe de la dependencia en la que obrare el expediente y cualquier otra persona responsable de la demora, imponiéndole en todo caso a aquél multa de cinco mil pesetas.

\section{SECCION TERCERA}

\section{Garantía jurisdiccional civil}

Artículo 11

1. Las reclamaciones por vulneración o desconocimiento de los dere- 
chos fundamentales de la persona, comprendidos en el ámbito de esta Ley, o para impugnar pretensiones relativas a los mismos, no comprendidas en los artículos segundo y sexto de la misma, se formularán ante los Juzgados de Primera Instancia correspondientes a la localidad donde se haya producido el hecho o donde radique el registro $u$ oficina en que deban manifestarse.

2. Las disposiciones de esta sección serán aplicables en todo caso cuando las Leyes reguladoras de los derechos fundamentales de la persona a que se refiere esta Ley establezcan alguna reclamación de orden civil.

\section{Artículo 12}

1. Están legitimados para actuar como demandantes el Ministerio Fiscal y las personas naturales o jurídicas titulares de un derecho subjetivo que lés faculte para obtener la declaración judicial pretendida.

2. Podrá intervenir en el proceso, como parte coadyuvante del demandante o del demandado, cualquier persona natural o jurídica que tuviere interés directo en el asunto.

3. El Ministerio Fiscal siempre será parte de estos procedimientos.

Artículo 13

1. El procedimiento será el establecido para los incidentes en la Ley de Enjuiciamiento Civil, con las siguientes especialidades.

Primera. El plazo de contestación a la demanda será común para todos los demandados e intervinientes.

Segunda. No cabrá el plazo extraordinario de prueba.

Tercera. La vista, en caso de solicitarse, habrá de celebrarse antes de los siete días siguientes al de formulación de la petición.

\section{Artículo 14}

1. La sentencia que recaiga será apelable en ambos efectos.

2. Podrán interponer el recurso quienes conforme al artículo doce se hallen legitimados para actuar como demandantes o demandados.

3. Los coadyuvantes no podrán recurrir con independencia de las partes principales.

\section{Artículo 15}

1. Las apelaciones se sustanciarán por los trámites establecidos en la 
sección tercera del título VI del libro II de la Ley de Enjuiciamiento Civil, con las siguientes modificaciones:

Primera. El plazo de pruebas, en su caso, será de diez días.

Segunda. La vista tendrá lugar dentro de los siete días siguientes a la conclusión del plazo concedido al ponente para instrucción.

Tercera. Entre la citación y la vista se pondrán los autos de manifiesto a las partes en la Secretaría, para que puedan instruirse de ellos.

2. Contra la sentencia dictada en apelación podrá interponerse recurso de casación o, en su caso, de revisión.

\section{DISPOSICION FINAL}

Dentro de los dos meses desde la entrada en vigor de la Constitución, y entre tanto se regula definitivamente el procedimiento jurisdiccional de amparo o tutela de los derechos reconocidos en la misma, el Gobierno, por Decreto legislativo, previa audiencia del Consejo de Estado, podrá incorporar al ámbito de protección de esta Ley los nuevos derechos constitucionalmente declarados que sean susceptibles de ella.

\section{DISPOSICION DEROGATORIA}

Se derogan los incisos B), C), D) y E) del apartado dos del artículo sesenta y cuatro de la vigente Ley de Prensa; el Real Decreto-ley veinticuatro/mil novecientos setenta y siete, de uno de abril, y el Real Decreto mil cuarenta y ocho/mil novecientos setenta y siete, de trece de mayo, y cualesquiera otras disposiciones que se opongan a lo prevenido en esta Ley.

\section{DISPOSICION TRANSITORIA}

1. Las causas que se encuentren en trámite, por acciones u omisiones comprendidas en el ámbito de aplicación de la presente Ley, se acomodarán a las prescripciones de ésta, cualquiera que fuera su estado, incluso en el supuesto de que hubiere recaído sentencia siempre que ésta no fuera firme.

2. Los Juzgados, Tribunales y autoridades de cualesquiera orden y jurisdicción distintas de las que componen la jurisdicción ordinaria, que estuvieren conociendo de actuaciones comprendidas en el ámbito de aplicación de la presente Ley, se inhibirán inmediatamente a favor de aquéllas. 
El Fiscal del Tribunal Supremo acordará lo conducente al cumplimiento de estas normas.

Dada en Madrid a veintiséis de diciembre de mil novecientos setenta y ocho.

\section{JUAN CARLOS}

El Presidente de las Cortes, ANTONIO HERNANDEZ GIL 